Article

\title{
Spatial Agglomeration Characteristics of Rural Settlements in Poor Mountainous Areas of Southwest China
}

\author{
Guanglian Luo ${ }^{1,2}$, Bin Wang ${ }^{3}$, Dongqi Luo ${ }^{4}$ and Chaofu Wei ${ }^{1, *}$ \\ 1 College of Resources and Environment, Southwest University, Chongqing 400715, China; lglzyx@163.com \\ 2 College of Tourism and Land resources, Chongqing Technology and Business University, \\ Chongqing 400067, China \\ 3 Chongqing Zhiheng Land Planning and Design co., LTD, Chongqing 400067, China; \\ wangbinchqzlpd@163.com \\ 4 Research Center of the Economy of the Upper Reaches of the Yangtze River of the Key Research Base of \\ Humanities, Ministry of Education, Chongqing Technology and Business University, \\ Chongqing 400067, China; luodongqi@ctbu.edu.cn \\ * Correspondence: weicf@swu.edu.cn
}

Received: 19 January 2020; Accepted: 26 February 2020; Published: 28 February 2020

check for updates

\begin{abstract}
The rural settlements in poverty-stricken mountainous areas are the "living fossils" of an economic society with the characteristics of spatial dispersion and are slowly changing. Spatial agglomeration is the development direction of rural settlements. In-depth exploration of the spatial agglomeration characteristics and influencing factors of rural settlements in poverty-stricken mountainous areas is a way to provide a basis for rural settlement restructuring. We selected Pengshui County, a national poverty-stricken county in the southwestern mountainous area of China, as the research area. Spatial buffer and kernel density analysis were used to analyze the agglomeration characteristics of rural settlements and influencing factors. The results show that: (1) The rural settlements are small in scale and the space is evenly dispersed. $55.63 \%$ of the rural settlements' sizes are less than $1000 \mathrm{~m}^{2}, 84.15 \%$ of the rural settlements' sizes are less than $2500 \mathrm{~m}^{2}$, and $92.81 \%$ of the rural settlements are within $200 \mathrm{~m}$. (2) The elevation and slope of topographic factors have a significant agglomeration effect on rural settlements. However, the slope direction has no agglomeration effect. $85.41 \%$ of rural settlements (52.75\% of rural settlements are gathered between 400 and $800 \mathrm{~m}$ above sea level) are gathered at an altitude of $1000 \mathrm{~m}$ or less, and $77.59 \%$ of rural settlements are gathered with a slope of $6 \sim 25^{\circ}$. Additionally, there are few rural settlements with a slope of $0 \sim 2^{\circ}$. Moreover, the distribution of residential areas has no agglomeration effect on rural settlements. (3) The cultivated land exerts the most significant effect on rural settlements followed by roads and water sources, while the role of urban land is weak. $99.48 \%$ of rural settlements are concentrated in the $100 \mathrm{~m}$ area of cultivated land. Therefore, in the poverty-stricken mountainous areas in the southwestern mountainous areas of China, convenient farming is the primary condition for production and living. Rural settlements are highly correlated with cultivated land. Rural settlements are scattered and concentrated with the scattered cultivated land. The rural settlements were leaded by the distribution of cultivated land. Less high-quality cultivated land with less slope were occupied or not by rural residential areas' people.
\end{abstract}

Keywords: poor mountainous areas; rural settlements; spatial agglomeration; mountainous area; southwest China 


\section{Introduction}

China is a mountainous country, with mountains accounting for two-thirds of the land area (http://www.gov.cn/guoqing/2005-09/13/content_2582624.htm\#1) [1]. At the end of 2018, the total population of mainland China was 1395.38 million, the permanent population of urban areas was 831.37 million (accounting for $59.58 \%$ of the total population), and the resident population of rural areas was 564.01 million (accounting for $40.42 \%$ of the total population). There are 16.60 million rural poor people and 585 national poverty-stricken counties, mostly distributed in mountainous areas (data from the National Rural Poverty Monitoring Survey of the National Bureau of Statistics of China) (http://www.stats.gov.cn/) [2]. In poor, mountainous areas, rural settlements are small in scale and scattered in space. It is not conducive to the infrastructure's construction and limits the full use of public resources, which has great obstacles to the development of agricultural industry and the healthy and comfortable life of rural residents. The spatial agglomeration of rural settlements can meet the needs of industrialized urbanization. The population succession at the county level includes five rising sequences of courtyards in China. They are village groups, villages, townships (towns), and counties (cities), forming two types of information transfer methods: administrative management and market economy. The rural settlements in the mountains have a long history. They have experienced dynasty changes, historical vicissitudes, and slow changes in the system, which have become the "living fossils" of the mountain economy and society. Spatial dispersion, living by mountain products on the mountain, staying away from economic centers, and staying away from cities are common development patterns for rural settlements in poor mountainous areas [3]. Residential areas include urban and rural settlements. Towns are generally surrounded by rural settlements. The difference between urban and rural areas is mainly reflected in the size and concentration of population. Moreover, the degree of agglomeration is the most significant difference between urban and rural areas. Studying the spatial agglomeration characteristics of rural settlements in poverty-stricken mountainous areas has important theoretical and practical significance for clarifying the status quo, exploring the causes and clarifying the development direction.

\section{Literature Review}

Arboreal, burrowing, housing, and settlement are the four stages in the evolution of human habitation [3]. In 1841, J.G. Kohl made a comparative study of different types of settlements, such as metropolis, market town and rural settlements, and introduced them into the study of geography, laying a foundation for the geography of settlements [4]. However, settlement geography remained a marginal subject until the end of the 20th century [5]. The most representative of rural development is the symbiotic model: namely agriculture-industrialization, post-production and rural sustainable development [6]. The spatial agglomeration of rural settlements is influenced by industrialization, reverse urbanization, globalization, tourism activities and emerging media [7]. In the western United States, the spatial agglomeration of rural settlements is influenced by immigration, the development of science and technology and the change of human-land relationship [8]. Rural settlements are no longer pure rural spaces [9]. The development of network and information technology shortens the distance between rural areas and the market, improves the opportunity of external learning, and thus promotes the development of rural areas [10]. With the integration of new disciplines and new technologies, the spatial agglomeration of rural settlements has become a research hotspot [11-19].

In China, around $100 \mathrm{BC}$, "living in one place in a year will become a settlement; two years will become a city and three years will become a metropolis" was noted in the "Records of the Grand Historian". Before and after A.D., "a settlement will be settled when building some rooms with no any disasters in a long time" was said in "Book of Han". At Qinba mountains in central China, rural settlements are mainly scattered and small in scale, and are also clustered along roads and rivers [20-22]. In western China, rural settlements in the western mountainous areas of Sichuan province are mainly affected by farming, most of which are below an altitude of $3500 \mathrm{~m}$ and distributed mostly in the alluvial fan area of the river valley, and the scale increases with the height decreasing and the area of the 
alluvial fan area expanding. The larger ones are distributed mostly at the confluence of the two rivers and distributed along the river valley (in a linear pattern) [23-25]. In west China, the density of rural settlements in the hilly and gully region of the Yilin Loess plateau in the north of Shanxi province is characterized by the spatial distribution along the geomorphic type, water source, elevation, traffic line and city (town) [26,27]. In western China, rural settlements in mountainous areas of Guizhou province are scattered along road branches and rivers in mountain and valley areas [28-30]. Rural settlements in mountainous areas of Yunnan province in western China are relatively small and scattered [31]. In a word, rural settlements in mountainous areas in China are small in scale and scattered in distribution. Affected by multiple factors, most of them are close to cultivated land and convenient for nearby planting [32].

Based on the relevant research results, Pengshui County is taken as an example, which is a national poverty-stricken county in Chongqing. In order to revitalize rural areas and realize spatial adjustment and reconstruction, the characteristics of rural settlement agglomeration and its influencing factors are studied by spatial buffering and kernel density analysis. Our study will provide a basis for providing similar ideas for conducting similar research in other regions.

\section{Study Area}

Pengshui County of Chongqing City is located in the southeast of Chongqing City (Figure 1), in the lower reaches of the Wujiang River, a tributary of the Yangtze River, between E107 $48^{\prime}-108^{\circ} 35^{\prime}$, $\mathrm{N} 28^{\circ} 57^{\prime}-29^{\circ} 50^{\prime}$. Pengshui County is connected with the Shizhu Tujia Autonomous County at north and bordered the Lichuan City, Enshi Tujia and Miao Autonomous Prefecture, Hubei Province at northeast. At east, this country is adjoined with Chongqing Qianjiang District. At southeast, it is Chongqing Youyang Tujia and Miao Autonomous County. At south, it is Guizhou Province along the river Tujia Autonomous County and Wuchuan Gelao and Miao Autonomous County. At southwest, it is Daozhen Gelao and Miao Autonomous County, Guizhou Province. At west, it is Wulong County, Chongqing. At northwest, it is bordered by Chongqing Fengdu County. Pengshui County is $77.88 \mathrm{~km}$ wide from east to west and $96.40 \mathrm{~km}$ distance from north to south, with a total area of $3903 \mathrm{~km}^{2}$. Pengshui County has 3 sub-district offices, 18 towns, 18 townships, 296 villages (residential). Pengshui County belongs to the Wuling Mountain System. It is high in the northwest and low in the southeast. The landform is characterized by "two mountains and one trough"; the hilly valley area accounts for $13.39 \%$, the low mountain area accounts for $52.88 \%$, and the middle mountain area accounts for $34.03 \%$. The highest elevation point of Pengshui County is $1859.60 \mathrm{~m}$, the lowest point is $190 \mathrm{~m}$, and the relative height difference is $1669.60 \mathrm{~m}$, which is the middle and low mountain topography of structural erosion. The Wujiang River traverses the whole territory from the southeast to the west, with a length of $64 \mathrm{~km}$ in the territory; there are more than 20 tributaries of Yujiang, Changxi River, Furong River and $\mathrm{Mu}$ Brown River. It belongs to the mid-subtropical humid monsoon climate, with mild climate, abundant rainfall, average annual temperature of $17.5^{\circ} \mathrm{C}$, annual average precipitation of $1228.7 \mathrm{~mm}$, annual sunshine duration of $1035.5 \mathrm{~h}$, and frost-free period of 311 days. The geological structure in Pengshui County belongs to Xinhua tectonic system. The outcrops mainly include Proterozoic Simian, Paleozoic Cambrian, Paleozoic Ordovician, Paleozoic Silurian, Paleozoic Devonian, Paleozoic Permian, Mesozoic Triassic, Mesozoic Jurassic and Cenozoic Quaternary. In Pengshui County, the surface is broken, the mountain slopes are steep and the soil erosion is serious. The main soil types are hilly and valley tidal soil, purple soil, yellow soil area $(11.90 \%)$, low, Zhongshan yellow soil area $(81.02 \%)$ and Zhongshan yellow-brown soil area (7.08\%) (http://www.psx.gov.cn/) [33].

At the end of 2016, the total registered population of Pengshui County was 702,900, and the urban population was 203,100 (accounting for $28.89 \%$ of the total population), the rural population was 499,800 (accounting for $71.11 \%$ of the total population), and the ethnic minorities with Miao nationality accounted for $62.40 \%$ of the total population. The quantity of households is 228,564 , which is a typical mountainous agricultural county. The GDP of the county is 12.87 billion yuan, and the per capita disposable income of rural residents is 9294 yuan. It ranks 31st in 38 districts (counties) in 
Chongqing, far below the average level of city, and its economic development is backward. It belongs to Wuling Mountain Area, a national poverty-stricken county in a particularly difficult area. Influenced by topography, river roads, economic level, and ideological concepts, the spatial difference of rural settlement areas in Pengshui County is significant.

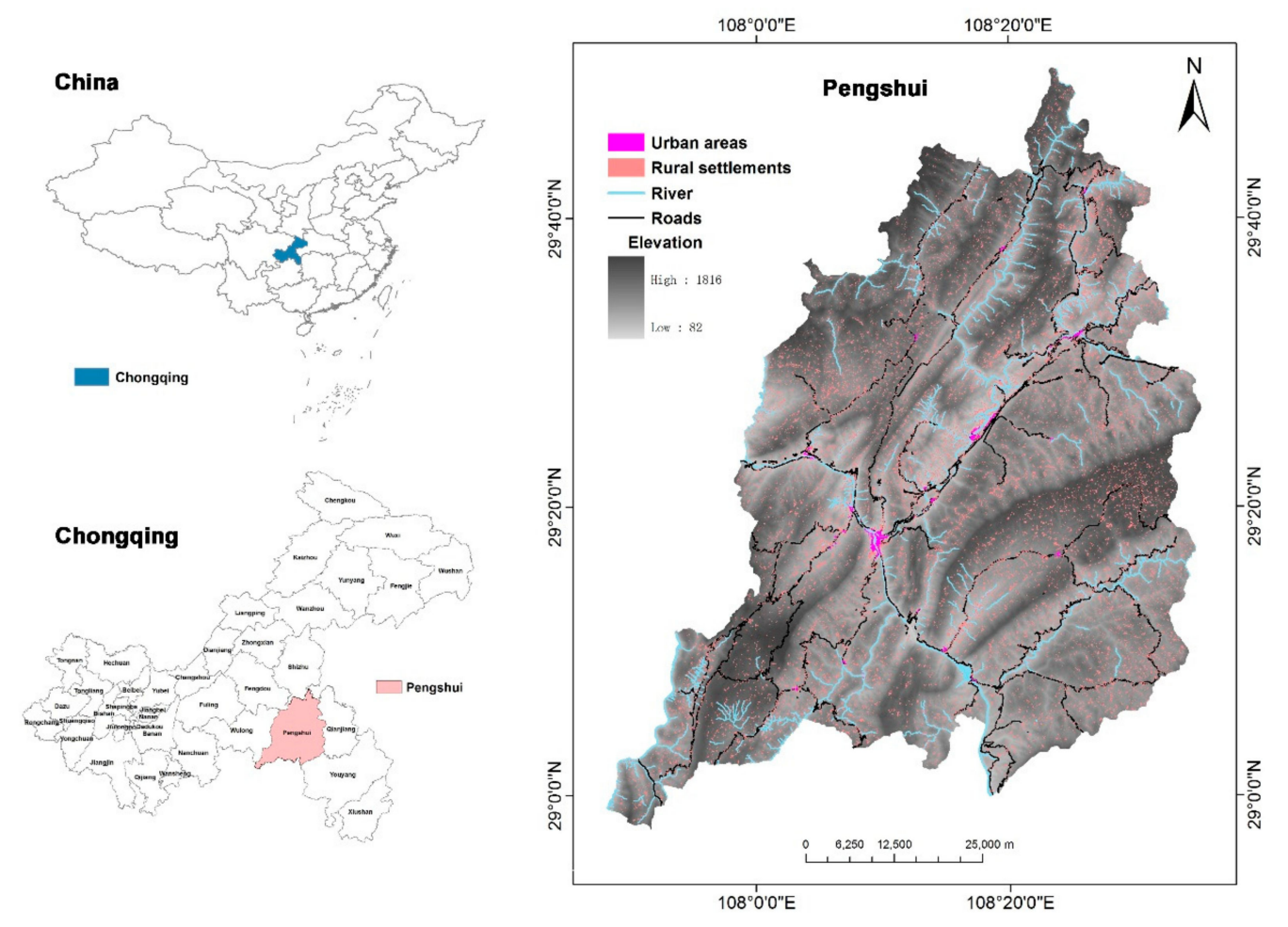

Figure 1. Geographical location of Pengshui County, Chongqing, China.

\section{Data Sources and Research Methods}

\subsection{Data Source and Processing}

This paper reveals the spatial agglomeration characteristics of rural settlement areas in Pengshui County, Chongqing, from the county level. By combining with research needs and data availability, rural settlements, towns, cultivated land and rivers, roads, etc., (Figure 1) were extracted based on the 2016 land use utilization database of Pengshui County. Grading, and superposition analysis were used for hierarchical statistics. The terrain data was derived from the digital elevation data of $30 \mathrm{~m}$ spatial resolution of the Geospatial Data Cloud Platform (http://www.gscloud.cn) [34] of the Computer Network Information Center of the Chinese Academy of Sciences. The economic data used in the study was derived from the 2017 Pengshui Statistical Yearbook.

\subsection{Research Methods}

\subsubsection{Spatial Buffer Analysis}

Spatial buffer analysis is the determination of their neighborhood for a given spatial object or set. The size of the domain is determined by the neighborhood radius $R$. Therefore, the buffer of object $O_{i}$ can be defined as [35]:

$$
B_{i}=\left\{x: \mathrm{d}\left(x, \mathrm{O}_{i}\right) \leq R\right\}
$$


That is, the buffer of object $O_{i}$ with the radius $R$ is a collection of all points with a distance $d$ from $O_{i}$ less than the distance $R$. $d$ is usually the minimum Euclidean distance, but it can also be defined distances. For object collection:

$$
O=\left\{\mathrm{O}_{i}: i=1,2, \cdots, n\right\}
$$

The buffer, whose radius $R$ is the sum of the buffers of each object, that is:

$$
B=\bigcup_{i=1}^{n} B_{i}
$$

\subsubsection{Kernel density analysis}

Kernel density analysis is used to calculate the spatial distribution of the observed object by calculating a certain regular area around any point in the space as the calculation range of the density. Data points that are closer to the center point are given a higher weight, while the further points are given a lower weight. The estimated density of each point is the weighted average density of all points in the area [36].

Among them, the kernel density $P_{i}$ at any point $i$ in the space is defined as the function of the highest at the center and decreasing outward. When the distance $R$ reaches a certain value, the density is 0 :

$$
P_{i}=\frac{1}{n \pi R^{2}} \times \sum_{j=1}^{n} K_{j}\left(1-\frac{D_{i j}^{2}}{R^{2}}\right)^{2}
$$

In Equation (4): $K_{j}$ is the weight of the research object $j ; D_{i j}$ is the distance between the spatial point $i$ and the research object $j$; $R$ is the bandwidth of the selected regular region $\left(D_{i j}<R\right) ; n$ is the quantity of research objects $j$ within the bandwidth $R$.

\section{Results and Analysis}

\subsection{Scale Agglomeration Characteristics of Rural Settlements}

(1) The average quantity of households is 3 , and more than half of the rural settlements have only $1 \sim 2$ households and 1 6 people.

At the end of 2016, the total population of the study area was 702,949, with a total of 228,564 households, including 203,141 urban population, 499,808 rural population, and about 3 persons per household. The per capita rural settlement land was $158.70 \mathrm{~m}^{2}$; the rural settlement should be $476.09 \mathrm{~m}^{2}$ (about $500 \mathrm{~m}^{2}$ ) per household. The average size of rural settlements is only about 3 households; the coefficient of variation (standard deviation/average) is 1.70, and the overall size difference is large (see Table 1).

Table 1. The scale characteristics of rural settlements in the study area.

\begin{tabular}{ccccccc}
\hline $\begin{array}{c}\text { The Total } \\
\text { Quantity }\end{array}$ & $\begin{array}{c}\text { Minimum } \\
\text { Area }\left(\mathbf{m}^{2}\right)\end{array}$ & $\begin{array}{c}\text { Maximum } \\
\text { Area }\left(\mathbf{m}^{2}\right)\end{array}$ & $\begin{array}{c}\text { Average } \\
\text { Area }\left(\mathbf{m}^{2}\right)\end{array}$ & $\begin{array}{c}\text { Total Area } \\
\left(\mathbf{h m}^{\mathbf{2}}\right)\end{array}$ & $\begin{array}{c}\text { Standard } \\
\text { Deviation }\left(\mathbf{m}^{2}\right)\end{array}$ & Density \\
\hline 47,844 & 29.62 & $127,087.84$ & 1708.77 & 8175.43 & 2892.60 & 12.26 \\
\hline
\end{tabular}

Taking households as a unit (1 household, 3 persons, $150 \mathrm{~m}^{2}$ per person, and $500 \mathrm{~m}^{2}$ per household), the data of rural settlements in the study area are extracted and classified (Table 2), with an area of less than $500 \mathrm{~m}^{2}$ (approximately 1 household). There are 10,371 rural settlements, accounting for $21.68 \%$ of the total; rural areas with an area of less than $1000 \mathrm{~m}^{2}$ (about 2 households) have 26,615, accounting for $55.63 \%$ of the total. Most rural settlements are small in size, with only 1 or 2 households living, only as a base for production, with few living facilities. In terms of quantity: the proportion of rural households with 2 households and 4 6 people is the largest (accounting for 33.95\%), and the cumulative proportion of rural households with $1 \sim 5$ households and that with $1 \sim 15$ people is $84.15 \%$; 
The proportion of rural residents with $6 \sim 10$ households and 16 30 people is the largest (accounting for $19.67 \%$ ), and the cumulative proportion of rural households with $2 \sim 50$ households and $4 \sim 150$ people is $90.70 \%$.

Table 2. Classification statistics of the rural settlements in the study area.

\begin{tabular}{ccccccc}
\hline $\begin{array}{c}\text { Quantity of } \\
\text { Households }\end{array}$ & $\begin{array}{c}\text { Quantity of } \\
\text { People }\end{array}$ & Scale $\mathbf{( m}^{\mathbf{2}} \mathbf{)}$ & $\begin{array}{c}\text { Area Summary } \\
\mathbf{( h m}^{\mathbf{2}} \mathbf{n}\end{array}$ & $\begin{array}{c}\text { Area Ratio } \\
\text { Summary (\%) }\end{array}$ & $\begin{array}{c}\text { Quantity } \\
\text { Summary }\end{array}$ & $\begin{array}{c}\text { Proportion of } \\
\text { Quantity (\%) }\end{array}$ \\
\hline 1 & 1 & $\leq 150$ & 1.98 & 0.02 & 178 & 0.37 \\
1 & $2-3$ & $150-500$ & 342.16 & 4.19 & 9247 & 19.33 \\
2 & $4-6$ & $500-1000$ & 1193.32 & 14.60 & 16,553 & 34.60 \\
3 & $7-9$ & $1000-1500$ & 948.73 & 11.60 & 7761 & 16.22 \\
$4-5$ & $10-15$ & $1500-2500$ & 1250 & 15.29 & 6527 & 13.64 \\
$6-10$ & $16-30$ & $2500-5000$ & 1628.59 & 19.92 & 4726 & 9.88 \\
$11-20$ & $31-60$ & $5000-10,000$ & 1381.22 & 16.89 & 2024 & 4.23 \\
$21-50$ & $61-150$ & $10,000-25,000$ & 1030.55 & 12.61 & 723 & 1.51 \\
$51-100$ & $151-300$ & $25,000-50,000$ & 306.11 & 3.74 & 92 & 0.19 \\
$101-200$ & $301-600$ & $50,000-100,000$ & 68.63 & 0.84 & 11 & 0.02 \\
$201-300$ & $601-900$ & $100,000-150,000$ & 24.14 & 0.30 & 2 & 0.00 \\
\hline
\end{tabular}

The above results indicate that most of the rural settlements in the study area are under 5 households and 15 people. No scale space agglomeration has yet been made.

\subsection{Spatial Agglomeration Characteristics of Rural Settlements}

(1) Most rural settlements are no more than $200 \mathrm{~m}$ apart.

According to the buffer analysis of rural settlements, when the buffer radius is $100 \mathrm{~m}, 92.81 \%$ of rural settlement points gather; while the buffer radius is $200 \mathrm{~m}, 99.18 \%$ of rural settlement points gather; and when the buffer radius is $700 \mathrm{~m}, 100 \%$ of rural settlement points gather. That is, all rural settlement point buffers are completely superimposed (Table 3). The above results show that the distance between most rural settlements is less than $200 \mathrm{~m}$, and only $7.19 \%$ of rural settlements are more than $200 \mathrm{~m}$ apart.

Table 3. Classification statistics of the rural settlements in the study area.

\begin{tabular}{ccccc}
\hline Buffer Radius (M) & $\begin{array}{c}\text { Agglomeration } \\
\text { Area } \mathbf{( h m}^{\mathbf{2}} \mathbf{)}\end{array}$ & $\begin{array}{c}\text { Area Ratio } \\
\mathbf{( \% )}\end{array}$ & $\begin{array}{c}\text { Agglomeration } \\
\text { Quantity }\end{array}$ & $\begin{array}{c}\text { Proportion of } \\
\text { Quantity (\%) }\end{array}$ \\
\hline $0-100$ & 7866.71 & 96.22 & 45,893 & 95.92 \\
$100-200$ & 268.97 & 3.29 & 1716 & 6.45 \\
$200-300$ & 33.81 & 0.41 & 189 & 5.65 \\
$300-400$ & 4.86 & 0.06 & 40 & 4.77 \\
$400-500$ & 0.83 & 0.01 & 5 & 4.71 \\
$500-600$ & 0.00 & 0.00 & 0 & 4.13 \\
$600-700$ & 0.25 & 0.00 & 1 & 3.87 \\
\hline
\end{tabular}

(2) The overall spatial dispersion of rural settlements, local agglomeration.

The total area of the study area is $3903 \mathrm{~km}^{2}$, including 47,844 rural settlements and an area of $81.75 \mathrm{~km}^{2}$. After the total area of the study area is deducted from the rural settlement, if the square is evenly distributed, the radiation area of each rural settlement (i.e., the agricultural production base) is $79,868.95 \mathrm{~m}^{2}$, and the ideal side length should be $282.61 \mathrm{~m}$. Combining with (Figure 1 ) and (Tables 1-3), $99.51 \%$ of the rural settlements in the study area are no more than $200 \mathrm{~m}$ apart, which is less than the ideal side length. The above results show that although the rural settlements in the study area are generally spatially dispersed, there is still agglomeration in the local area.

Using the Feature To Point module of ArcGIS 10.2 software, the center point of the rural settlement map is extracted, and the density map was generated by the kernel method (Figure 2). The high-density 
area of the rural settlement presents the "Northeast-Southwest" strip phenomenon. It is in line with the terrain and is in the trough area of "two mountains and one trough".

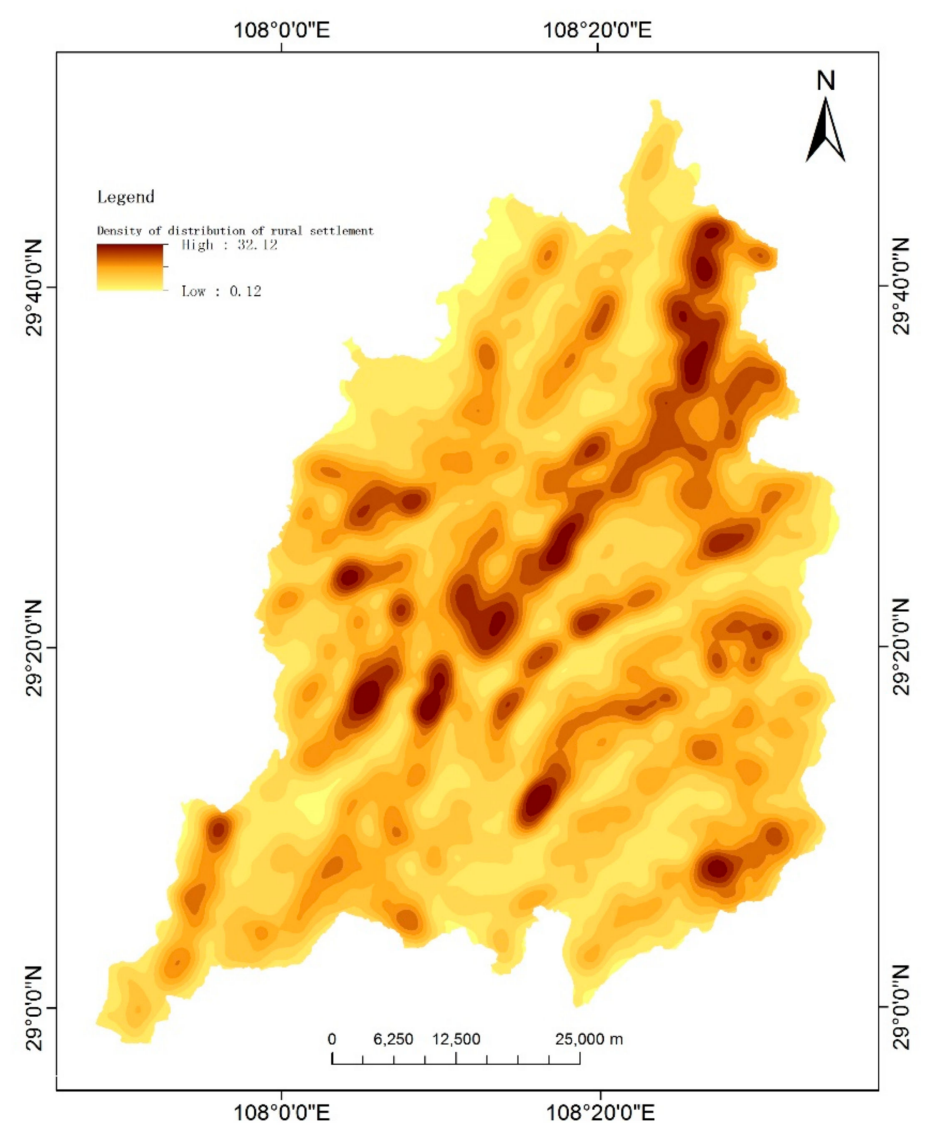

Figure 2. Density of distribution of rural settlement in the study area.

\subsection{Topographical Agglomeration Characteristics of Rural Settlements}

(1) The rural settlements are concentrated between the elevation of $400 \sim 800 \mathrm{~m}$.

By using the software, ArcGIS 10.2, the rural settlements and elevations (DEM) were superimposed to extract the elevation values of each rural settlement and carry out hierarchical statistics (Table 4). From the area, $85.41 \%$ of the rural settlements in the study area are distributed below $1000 \mathrm{~m}$ above sea level, especially at an altitude of $400 \sim 800 \mathrm{~m}$, accounting for $52.75 \%$ of the total area. In terms of quantity, $84.28 \%$ of the rural settlements in the study area are distributed at an altitude of $1000 \mathrm{~m}$ or less, especially at an altitude of $400 \sim 800 \mathrm{~m}$, accounting for $52.69 \%$ of the total. Therefore, regardless of the area or quantity, rural settlements are mainly concentrated in the area of $400 \sim 800 \mathrm{~m}$ above sea level.

Table 4. Distribution of the rural settlements to elevation in the study area.

\begin{tabular}{ccccc}
\hline Elevation $(\mathbf{m})$ & Area Summary $\left.\mathbf{( h m}^{\mathbf{2}}\right)$ & Area Ratio $\mathbf{( \% )}$ & Quantity Summary & Proportion of Quantity (\%) \\
\hline $0-200$ & 20.91 & 0.26 & 69 & 0.15 \\
$200-400$ & 1170.29 & 14.31 & 5597 & 11.70 \\
$400-600$ & 1697.84 & 20.77 & 10,278 & 21.48 \\
$600-800$ & 2614.68 & 31.98 & 14,932 & 31.21 \\
$800-1000$ & 1478.55 & 18.09 & 9446 & 19.74 \\
$1000-1200$ & 680.55 & 8.32 & 4326 & 9.04 \\
$1200-1400$ & 456.08 & 5.58 & 2705 & 5.66 \\
$1400-1600$ & 56.36 & 0.69 & 489 & 1.02 \\
$1600-2000$ & 0.17 & 0.00 & 2 & 0.00 \\
\hline
\end{tabular}

(2) The rural settlements are concentrated at the slope of $6 \sim 25^{\circ}$, especially between $6 \sim 15^{\circ}$. 
By using the software, ArcGIS 10.2, elevation analysis module was used to generate the slope map based on elevation (DEM). The rural settlements and slope maps were superimposed to extract the slope values of each rural settlement and rank statistics (Table 5). From the area, 77.59\% of rural settlements are concentrated in the range of $6 \sim 25^{\circ}$, especially $6 \sim 15^{\circ}$, accounting for $46.65 \%$. In terms of quantity, $76.75 \%$ of rural settlements are concentrated in the range of $6 \sim 25^{\circ}$, especially $6 \sim 15^{\circ}$, accounting for $43.17 \%$. Therefore, regardless of the area or quantity, rural settlements exhibit the same agglomeration pattern on the slope. At the same time, the rural settlement has the least spatial distribution in the $0 \sim 2^{\circ}$ slope, and there are still about $10 \%$ rural settlement points in the area above $25^{\circ}$. The above results show: 1) In poor mountainous areas, agricultural farming is at the forefront, and cultivated land is the most valuable production resource, and construction is not occupied as much as possible. 2) The layout of rural settlements can be selected in a wide range, and cultivated land is mainly affected by natural factors. 3) In the poverty-stricken mountainous areas dominated by the rural areas, the Pingba area with good soil and water is mainly used for agricultural production, and rural areas with poor production conditions are used to build rural settlements.

Table 5. Distribution of the rural settlements to gradient in the study area.

\begin{tabular}{ccccc}
\hline Slope $\mathbf{( m )}$ & Area $\left.\mathbf{( h m}^{\mathbf{2}}\right)$ & Area Ratio $\mathbf{( \% )}$ & Quantity & Proportion of Quantity (\%) \\
\hline $0-200$ & 20.91 & 0.26 & 69 & 0.15 \\
$200-400$ & 1170.29 & 14.31 & 5597 & 11.70 \\
$400-600$ & 1697.84 & 20.77 & 10,278 & 21.48 \\
$600-800$ & 2614.68 & 31.98 & 14,932 & 31.21 \\
$800-1000$ & 1478.55 & 18.09 & 9446 & 19.74 \\
$1000-1200$ & 680.55 & 8.32 & 4326 & 9.04 \\
$1200-1400$ & 456.08 & 5.58 & 2705 & 5.66 \\
$1400-1600$ & 56.36 & 0.69 & 489 & 1.02 \\
$1600-2000$ & 0.17 & 0.00 & 2 & 0.00 \\
\hline
\end{tabular}

(3) The effect of slope direction accumulation is not obvious.

By using the software, ArcGIS 10.2, elevation analysis module was used to generate the aspect map based on elevation (DEM), and the rural slope points are superimposed with rural settlements to extract the slope value of each rural settlement and perform hierarchical statistics (Table 6). Regardless of the area or the proportion of the population, the slope characteristics of rural settlements in the study area are not significant, and the distribution of the slope direction is relatively uniform, and the proportion of the eastward and southeast directions is slightly larger than other directions. Compared to the analysis results with the field survey, the rural settlements in poor mountainous areas are inclined to back the mountain, and the orientation is not fixed due to the situation of the mountain.

Table 6. Distribution of the rural settlements to slope direction in the study area.

\begin{tabular}{ccccc}
\hline Slope Direction & Area $\mathbf{( h m}^{\mathbf{2}} \mathbf{)}$ & Area Ratio (\%) & Quantity & Proportion of Quantity (\%) \\
\hline North & 774.40 & 9.47 & 4681 & 9.78 \\
Northeast & 941.66 & 11.52 & 5674 & 11.86 \\
East & 1288.49 & 15.76 & 7442 & 15.56 \\
Southeast & 1357.84 & 16.61 & 7748 & 16.19 \\
South & 985.56 & 12.06 & 5648 & 11.81 \\
Southwest & 913.59 & 11.17 & 5406 & 11.30 \\
West & 970.69 & 11.87 & 5693 & 11.90 \\
Northwest & 943.20 & 11.54 & 5552 & 11.60 \\
\hline
\end{tabular}

\subsection{Water Source Agglomeration Characteristics of Rural Settlements}

By using the software, ArcGIS 10.2, buffer analysis module was used to generate buffers based on rivers and to superimpose statistics with rural settlements (Table 7 ). In terms of area ratio, $49.56 \%$ of 
the rural settlements in the study area are concentrated in the area $1000 \mathrm{~m}$ away from the river, and only $11.27 \%$ of the rural settlements are concentrated in the area $100 \mathrm{~m}$ away from the river. In terms of the proportion, $48.77 \%$ of the rural settlements in the study area are concentrated in the area 1000 $\mathrm{m}$ away from the river, and only $8.80 \%$ of the rural settlements are concentrated in the area $100 \mathrm{~m}$ away from the river. Therefore, regardless of the area or quantity, the water source agglomeration characteristics of rural settlements in the study area are more significant, but $30 \%$ of rural settlements are still distributed in areas other than $2000 \mathrm{~m}$ from the water source.

Table 7. Distribution of the rural settlements to water source in the study area.

\begin{tabular}{ccccc}
\hline Distance $(\mathbf{m})$ & Area $\left.\mathbf{( h m}^{\mathbf{2}}\right)$ & Area Ratio $\mathbf{( \% )}$ & Quantity & Proportion of Quantity (\%) \\
\hline $0-100$ & 921.43 & 11.27 & 4211 & 8.80 \\
$100-200$ & 501.18 & 6.13 & 3085 & 6.45 \\
$200-300$ & 440.00 & 5.38 & 2705 & 5.65 \\
$300-400$ & 389.51 & 4.76 & 2281 & 4.77 \\
$400-500$ & 384.46 & 4.70 & 2247 & 4.71 \\
$500-600$ & 327.22 & 4.01 & 1978 & 3.13 \\
$600-700$ & 300.99 & 3.68 & 1853 & 3.75 \\
$700-800$ & 287.91 & 3.52 & 1795 & 3.51 \\
$800-900$ & 252.81 & 3.09 & 1674 & 3.13 \\
$900-1000$ & 245.94 & 3.02 & 1499 & 2.92 \\
$1000-1100$ & 211.31 & 2.58 & 1397 & 2.76 \\
$1100-1200$ & 215.12 & 2.63 & 1321 & 2.30 \\
$1200-1300$ & 184.72 & 2.26 & 1101 & 1.85 \\
$1300-1400$ & 168.53 & 2.06 & 1075 & 8.35 \\
$1400-1500$ & 144.37 & 1.77 & 887 & 12.40 \\
$1500-2000$ & 663.52 & 8.12 & 3997 & 7.65 \\
$2000-3000$ & 957.86 & 11.72 & 5932 & 10.75 \\
$3000-4000$ & 623.37 & 7.62 & 3662 & \\
$>4000$ & 955.18 & 11.68 & 5144 & \\
\hline
\end{tabular}

\subsection{Road Agglomeration Characteristics Of Rural Settlements}

By using the software, ArcGIS 10.2, based on road generation buffers, buffer analysis module was superimposed with rural settlements (Table 8). From the area ratio, $52.25 \%$ of the rural residential areas in the study area are concentrated in the $1000 \mathrm{~m}$ road area, and only $19.57 \%$ are concentrated in the road 100 $\mathrm{m}$ range. In terms of the proportion, $49.99 \%$ of rural settlements are concentrated in the area of $1000 \mathrm{~m}$ roads, and only $16.41 \%$ are concentrated in the area of $100 \mathrm{~m}$ roads. Therefore, regardless of the area or quantity, road agglomeration characteristics of rural settlements in the study area are more significant, but there are still $25 \%$ of rural settlements distributed in areas other than $2000 \mathrm{~m}$ from the road.

Table 8. Distribution of the rural settlements to road in the study area.

\begin{tabular}{ccccc}
\hline Distance $(\mathbf{m})$ & Area $\left.\mathbf{( h m}^{\mathbf{2}}\right)$ & Area Ratio $\mathbf{( \% )}$ & Quantity & Proportion of Quantities $\mathbf{( \% )}$ \\
\hline $0-100$ & 1599.70 & 19.57 & 7850 & 16.41 \\
$100-200$ & 369.60 & 4.52 & 2294 & 4.79 \\
$200-300$ & 315.61 & 3.86 & 1983 & 4.14 \\
$300-400$ & 321.14 & 3.93 & 1911 & 3.99 \\
$400-500$ & 322.60 & 3.95 & 1886 & 3.94 \\
$500-600$ & 309.36 & 3.78 & 1849 & 3.86 \\
$600-700$ & 259.13 & 3.17 & 1675 & 3.50 \\
$700-800$ & 266.54 & 3.26 & 1613 & 3.37 \\
$800-900$ & 257.25 & 3.15 & 1462 & 2.06 \\
$900-1000$ & 250.66 & 3.07 & 1396 & 2.83 \\
$1000-1100$ & 227.10 & 2.78 & 1352 & 3.01 \\
$1100-1200$ & 229.89 & 2.81 & 1441 & 2.70 \\
$1200-1300$ & 204.68 & 2.50 & 1293 & 2.46 \\
$1300-1400$ & 199.81 & 2.44 & 1175 & 2.53 \\
$1400-1500$ & 198.46 & 2.43 & 1210 & 10.16 \\
$1500-2000$ & 795.97 & 9.74 & 4861 & 6.55 \\
$2000-3000$ & 1061.54 & 12.98 & 6481 & 5.79 \\
$3000-4000$ & 558.06 & 6.83 & 3342 & \\
$>4000$ & 428.32 & 5.24 & 2770 & \\
\hline
\end{tabular}


Combining (Table 7) with (Table 8), the rural settlements in the study area show the following rules along the water source and the road: (1) Small peaks appear simultaneously in the buffer zones of $0 \sim 100 \mathrm{~m}, 1500 \sim 2000 \mathrm{~m}, 2000 \sim 3000 \mathrm{~m}$, and (2) those small peaks are very similar. (3) In the same agglomeration area, the agglomeration characteristics of roads are slightly more significant than water sources.

\subsection{Characteristics of Cultivated Land Agglomeration in Rural Settlements}

By using the software, ArcGIS 10.2, based on the cultivated land generation buffer, buffer analysis module was superimposed with rural settlements (Table 9). From the area ratio, $99.55 \%$ of the rural settlements in the study area gather in $100 \mathrm{~m}$ of cultivated land. In terms of quantity, $99.48 \%$ of the rural settlements in the study area are concentrated in the area of $100 \mathrm{~m}$ of cultivated land. Therefore, regardless of the area or quantity, the characteristics of rural settlements in the study area are very significant.

Table 9. Distribution of the rural settlements to cultivated land in the study area.

\begin{tabular}{ccccc}
\hline Distance $(\mathbf{m})$ & Area $\mathbf{( h m}^{\mathbf{2}} \mathbf{)}$ & Area Ratio $\mathbf{( \% )}$ & Quantity & Proportion of Quantity (\%) \\
\hline $0-100$ & 8139.05 & 99.55 & 47,597 & 99.48 \\
$100-200$ & 20.28 & 0.25 & 171 & 0.36 \\
$200-300$ & 10.53 & 0.13 & 49 & 0.10 \\
$300-400$ & 3.40 & 0.04 & 20 & 0.04 \\
$400-500$ & 1.88 & 0.02 & 5 & 0.01 \\
$500-600$ & 0.19 & 0.00 & 1 & 0.00 \\
$600-700$ & 0.00 & 0.00 & 0 & 0.00 \\
$700-800$ & 0.00 & 0.00 & 0 & 0.00 \\
$800-900$ & 0.11 & 0.00 & 1 & 0.00 \\
\hline
\end{tabular}

\subsection{Urban Agglomeration Characteristics of Rural Settlements}

By using the software, ArcGIS 10.2, based on town-generated buffers, buffer analysis module was used to superimpose statistics with rural settlements (Table 10). Regardless of the area or the proportion, there is a distribution in the buffer radius of $0 \sim 4000 \mathrm{~m}$, and there is no obvious peak. Even in the distance of $4000 \mathrm{~m}$ from the town, there are still nearly $50 \%$ of rural settlements in the study area. It shows that the urban agglomeration of rural areas in the study area is not significant.

Table 10. Distribution of the rural settlements to urban in the study area.

\begin{tabular}{ccccc}
\hline Distance $(\mathbf{m})$ & Area $\mathbf{( h m}^{\mathbf{2}} \mathbf{)}$ & Area Ratio $\mathbf{( \% )}$ & Quantity & Proportion of Quantity (\%) \\
\hline $0-100$ & 290.74 & 3.56 & 811 & 1.70 \\
$100-200$ & 95.89 & 1.17 & 463 & 0.97 \\
$200-300$ & 101.19 & 1.24 & 484 & 1.01 \\
$300-400$ & 88.37 & 1.08 & 399 & 0.83 \\
$400-500$ & 69.81 & 0.85 & 435 & 0.91 \\
$500-600$ & 83.06 & 1.02 & 474 & 0.99 \\
$600-700$ & 85.01 & 1.04 & 452 & 0.94 \\
$700-800$ & 77.64 & 0.95 & 479 & 1.00 \\
$800-900$ & 94.24 & 1.15 & 505 & 1.06 \\
$900-1000$ & 78.16 & 0.96 & 554 & 1.16 \\
$1000-1100$ & 97.33 & 1.19 & 592 & 1.24 \\
$1100-1200$ & 97.88 & 1.20 & 566 & 1.18 \\
$1200-1300$ & 84.85 & 1.04 & 535 & 1.12 \\
$1300-1400$ & 95.30 & 1.17 & 551 & 1.15 \\
$1400-1500$ & 92.15 & 1.13 & 536 & 1.12 \\
$1500-2000$ & 505.66 & 6.19 & 3083 & 6.44 \\
$2000-3000$ & 1155.62 & 14.14 & 6923 & 14.47 \\
$3000-4000$ & 999.45 & 12.23 & 6054 & 12.65 \\
$>4000$ & 3983.06 & 48.72 & 23,948 & 50.05 \\
\hline
\end{tabular}

\subsection{Differences in Agglomeration Characteristics of Rural Settlements}

According to Tables 1-10 by comparing the agglomeration characteristics of different factors affecting the spatial distribution of rural settlements in the study area, we found: 1) The topography 
(elevation, slope), roads, water sources and cultivated land of the study area have agglomeration effect on the distribution of rural settlements, while towns and slopes do not. The effect on agglomeration is not significant; 2) The distribution of cultivated land to rural settlements is very significant; 3) The agglomeration presents cultivated land $>$ elevation $>$ road $\geq$ water source $>$ slope $>$ field town $>$ slope direction.

\section{Discussion and Conclusions}

\subsection{Discussion}

On the basis of the land use database, the techniques and methods of exploratory spatial data analysis such as spatial buffering and kernel density analysis are used to analyze the spatial agglomeration characteristics and environmental factors of rural settlements in the study area. In poor mountainous areas, convenient farming is the primary condition for production and life. Elevation and slope affect the distribution of agricultural resources such as light, temperature and water, thus affecting farming and the distribution of rural settlements. Rural settlements are highly correlated with cultivated land. Rural settlements are scattered and gathered together with cultivated land, and $99.48 \%$ of rural settlements are concentrated within the $100 \mathrm{~m}$ area of cultivated land. The distribution of cultivated land dominates the concentration of rural settlements. In the poverty-stricken mountainous areas, cultivated land is the most valuable resource, and rural settlements do not occupy and occupy less high-quality cultivated land with less slope. There are very few rural settlements in the $0-2^{\circ}$ slope, and $77.59 \%$ of rural settlements are concentrated in the $6-25^{\circ}$ slope area, which fully reflects that the high-quality cultivated land with smaller slope is preferentially used for agricultural production rather than rural settlement development.

The economic and social factors such as cities and towns are not significant for the accumulation of rural settlements. From the area or quantity ratio, there are distributions within the range of $0 \sim 4000 \mathrm{~m}$ from the town; even beyond $4000 \mathrm{~m}$ from the town, there are nearly $50 \%$ of rural settlements, indicating that the urban agglomeration effect on rural settlements is not significant.

These findings highlight the central role of agriculture in supporting the traditional communities in the mountainous areas. The economic weakness will be enlarged with the accelerated urbanization and declining role of agriculture, which implies an urgent need to reconstruct the rural settlement pattern and industrial transformation. However, given the natural and economic conditions, it should be emphasized that the livelihoods' transformation, improvement of living conditions and ecological protection should be integrated into the planning of settlement reconstruction and rural revitalization.

\subsection{Conclusions}

In this paper, we employed spatial buffer and kernel density to analyze the spatial agglomeration characteristics of rural settlement in Pengshui County. We found that there is a high spatial correlation between rural settlements and cultivated land in poverty-stricken mountainous areas. The rural settlements are not more than $100 \mathrm{~m}$ away from cultivated land. It is highly anastomosed to the view that "the rural residential areas in mountainous areas of China are scattered by cultivated land, and concentrated living is not conducive to nearby planting", proposed by Jin Qiming [32]. Although the spatial distribution of cultivated land is the result of the combined effects of nature, economy and society, natural factors dominate. The spatial pattern of rural settlements in poverty-stricken mountainous areas under the guidance of agricultural farming is controlled by the quantity and quality distribution of cultivated land. The quantity and quality distribution of cultivated land are mainly controlled by natural factors. In other words, in poor mountainous areas, the spatial agglomeration of rural settlements is largely a natural process. When the economic and social pillars of poor mountainous areas are transformed from agricultural farming to industrialization or going out to work, the close relationship between rural settlements and cultivated land will undergo fundamental changes. Due to the change of rural settlements, arable land in mountainous areas is often abandoned [37-39]. In the 
process of rural revitalization, the adjustment and optimization of rural settlement space and the abandonment of cultivated land and the protection of cultivated land should be considered. The next step we will study is the coupling relationship between rural settlements and cultivated land in poor mountainous areas, and the possibility of predicting decoupling.

Author Contributions: Conceptualization, G.L.L.; methodology, G.L.L and C.F.W; software, B.W. and D.Q.L.; validation, D.Q.L. and C.F.W.; formal analysis, C.F.W.; investigation, G.L.L; resources, D.Q.L. and C.F.W; data curation, B.W.; writing-original draft preparation, G.L.L.; writing-review and editing, G.L. Land C.F.W; visualization, B.W.; supervision, C.F.W.; project administration, G.L.L; funding acquisition, G.L.Land C.F.W. All authors have read and agreed to the published version of the manuscript.

Funding: This work was supported by the Chongqing education commission science and technology project (No. KJ100712).

Conflicts of Interest: The authors declare no conflict of interest.

\section{References}

1. The State Council of the People's Republic of China. Available online: http://www.gov.cn (accessed on 20 December 2019).

2. National Bureau of Statistics of the People's Republic of China. Available online: http://www.stats.gov.cn/. (accessed on 20 December 2019).

3. Chen, G.J.F.Y.P.; Chen, Y. The Mountain Development Report of China: Studying on Mountainous Settlements in China; The Commercial Press: Beijing, China, 2007. (In Chinese)

4. Gill Valentine. Social Geographies, Space and Society; Prentice Hall: Upper Saddle River, NJ, USA, 2001.

5. Cater, J.; Jones, T. Society Geography, An introduction to Contemporary Issues. Edward Arnold: London, UK, 1989.

6. Roche, M. Rural geography: a stock tally of 2002. Prog. Hum. Geogr. 2003, 7, 779-786. [CrossRef]

7. Pretty, J. The Living Land: Agriculture, Food and Community Regeneration in Rural Europe; Earthscan Publications Ltd.: London, UK, 1998.

8. Nelson, P.B. Rural restructuring in the American West: land use, family and discourse. J. Rural Stud. 2001, 17, 395-407. [CrossRef]

9. Mormon, M. Who is rural Or how to be rural: towards a sociology of the rural. In Rural Restructuring; Marsden, T., Low, P., Whatmore, S., Eds.; David Fulton: London, UK, 1990.

10. Grimes, S. Rural areas in the information society: diminishing distance or increasing learning capacity? J. Rural Stud. 2000, 13-21. [CrossRef]

11. GILG, A.W. Countryside planning; Routledge: London, UK, 1997.

12. Lewis, P.H. Tomorrow by design — a regional design process for sustainability. John Wiley \& sons Inc.: Hoboken, NJ, USA, 1998; pp. 33-43.

13. Long, H.l.; Liu, Y.S.; Wu, X.Q.; Dong, G.H. Spatio-temporal dynamic patterns of farmland and rural settlements in Su-Xi-Chang region: Implications for building a new countryside in coastal China. Land Use Policy 2009, 26, 322-333. [CrossRef]

14. Dalkmann, H.; Hutfilter, S.; Vogelpohl, K.; Schnabel, P. Sustainable mobility in rural China. J. Environ. Manag. 2008, 87, 249-261. [CrossRef]

15. Clark, J.K.; McChesney, R.; Munroe, D.K.; Irwin, E.G. Spatial characteristics of exurban settlement pattern in the United States. Landscape Urban Plan 2009, 90, 178-188. [CrossRef]

16. Mann, S. Institutional causes of urban and rural sprawl in Switzerland. Land Use Policy 2009, 26, 919-924. [CrossRef]

17. Li, X.; Liu, Y.; Chen, Y.; Li, P.; Yu, Z. Village Regrouping in the Eastern Plains of China: A Perspective on Home-Field Distance. Sustainability 2019, 11, 1630. [CrossRef]

18. Wang, J.; Zhang, W.; Zhang, Z. Quantifying the Spatio-Temporal Dynamics of Rural Settlements and the Associated Impacts on Land Use in an Undeveloped Area of China. Sustainability 2018, 10, 1490. [CrossRef]

19. Peng, Y.; Li, X.; Huang, L.; Jiang, S.; Xu, Y.; Lai, Y. Risks of Developing Concentrated Rural Settlement after the Wenchuan Earthquake in China. Sustainability 2018, 10, 1569. [CrossRef]

20. Chao, L.; Lou, T.M.; Guo, L.Z. The geographic investigation report of Daba Mountain. Acta Geogr. Sin. 1935, 3, 1-4. (In Chinese) 
21. Sun, J.W.; Luo, J.; Kong, X.S. Zoning and potential calculation for rural settlements zoning settlements consolidation in Qinba mountainous area based on spatial consolidation spatial characteristics. Hum. Geogr. 2017, 80-87. (In Chinese)

22. Zhang, H.W.; Wang, Z.Q.; Chai, J.; Wei, C.; Chen, Y.L. The Evaluation of Suitability of Rural Residential Land Consolidation based on the "Source-Sink" Landscape Theory: A Case Study of Fang County, Shiyan City, Hubei Province. China Land Sci. 2018, 32, 65-71. (In Chinese)

23. Zhu, B.H. Village distribution observed in Sikang mountain region. Acta Geogr. Sin. 1939, 6, 40-43. (In Chinese)

24. Feng, W.L.; Zhou, W.C.; Li, A.N.; Zhang, B.L. GIS-based spatial analysis on rural settlement centralization in the upper Minjiang river basin: a case study of Maoxian basin. Resour. Environ. Yangtze Basin 2008, 17, 57-61. (In Chinese)

25. Li, X.D.; Yang, Y.; Yang, B.; Zhao, T.; Yu, Z.R. Layout optimization of rural settlements in mountainous areas based on farming radius analysis. Trans. Chin. Soc. Agric. Eng. 2018, 34, 267-273. (In Chinese)

26. Yin, H.T.; Chen, Z.X. Spatial distribution and evolution of the rural settlements in Shaanxi province. Hum. Geogr. 1995, 10, 17-24. (In Chinese)

27. Tang, G.A.; Zhao, M.D. A GIS based research on the distribution of rural settlements-Taking Yulin area as an example. Economic Geography 2000, 20, 1-4. (In Chinese)

28. Gao, H.J.; Zhang, C.Q.; Cai, G.P.; Luo, X.Q. Land suitability evaluation of rural settlements in karst mountains based on GIS. Res. Soil Water Conserv. 2015, 22, 200-203,346. (in Chinese).

29. Lu, D.B.; Yang, J.; Mao, W.L.; Yu, Z.; Wang, Z.J.; Bai, B. Research on Spatial Distribution Characteristics and Space Reconstruction Of Rural Settlements In Mountainous Areas. Res. Environ. Yangtze Basin 2017, 26, 238-245. (In Chinese)

30. Lu, D.B.; Mao, W.L.; Yu, Z.; Bai, B. Simulation study on the spatial growth of rural settlements in the mountainous area based on improved MCR model. Res. Soil Water Conserv. 2016, 23, 322-326. (In Chinese)

31. Zhang, T.Z.; Zhang, F.R.; Xie, Z.; Huang, J.W. Spatial pattern evolution of rural settlements in mountainous areas of ethnic minorities in Yunnan Province under background of precise poverty alleviation. Trans. Chin. Soc. Agric. Eng. 2019, 35, 246-254. (In Chinese)

32. Jin, Q. Rural Geography. Education Publishing House: Nanjing, China, 1990. (In Chinese)

33. Pengshui County People's Government of Chongqing Municipality. Available online: http://www.psx.gov.cn/ (accessed on 20 December 2019).

34. Geospatial Data Cloud site, Computer Network Information Center, Chinese Academy of Sciences. Available online: http://www.gscloud.cn. (accessed on 20 December 2019).

35. Wu, L.; Liu, Y. Geographic information system: theories, methods and applications. Science Press: Beijing, China, 2001; pp. 159-168. (In Chinese)

36. Xu, Z.; Gao, X.L. A novel method for identifying the boundary of urban built-up areas with POI data. Acta Geogr. Sin. 2016, 71, 928-939. (In Chinese)

37. Shao, J.A.; Zhang, S.C.; Li, X.B. Effectiveness of farmland d transfer in alleviating farmland abandonment in mountain regions J. Geogr. Sci. 2016, 26, 203-218. [CrossRef]

38. Wang, Q.; Qiu, J.-J.; Yu, J. Does rural resettlement accelerate farmland abandonment in mountainous areas: A case study of 1578 households in Southern Shaanxi. J. Natural Resour. 2019, 34, 1376-1390. (In Chinese)

39. Li, S.F.; Li, X.B.; Xin, L.J.; Wang, R.; Wang, Y. Extent and distribution of cropland abandonment in Chinese mountainous areas. Resour. Sci. 2017, 39, 1801-1811. (In Chinese)

(C) 2020 by the authors. Licensee MDPI, Basel, Switzerland. This article is an open access article distributed under the terms and conditions of the Creative Commons Attribution (CC BY) license (http://creativecommons.org/licenses/by/4.0/). 